\title{
AN ASSESSMENT OF HELIUM EVOLUTION FROM HELIUM-SATURATED PROPELLANT DEPRESSURIZATION IN SPACE ${ }^{1}$
}

Bich N. Nguyen

The Boeing Company

Reusable Space Systems

Dr. Frederick Best, Director

Center for Space Power

Texas A\&M University
Tony Wong

The Boeing Company

Expandable Launch Systems

Cable Kunwitz

Interphase Transport Phenomena Laboratory

Department of Nuclear Engineering

Texas A\&M University

\section{ABSTRACT}

Helium evolution from the transfer of helium-saturated propellant in space is quantified to assess its impacts from creating two-phase gas/liquid flow from the supply tank, gas injection into the receiving tank, and liquid discharge from the receiving tank. Propellant transfer takes place between two similar tanks whose maximum storage capacity is approximately $2.55 \mathrm{~m}^{3}$ each. The maximum onorbit propellants transfer capability is $9000 \mathrm{lbm}$ (fuel and oxidizer). The transfer line is approximately $1.27 \mathrm{~cm}$ in diameter and $6096 \mathrm{~cm}$ in length and comprised of the fluid interconnect system (FICS), the orbiter propellant transfer system (OPTS), and the International Space Station (ISS) propulsion module (ISSPM). The propellant transfer rate begins at approximately 11 liter per minute (Ipm) and subsequently drops to approximately $0.5 \mathrm{lpm}$. The tank nominal operating pressure is approximately $1827 \mathrm{kPa}$ (absolute).

The line pressure drops for Monomethylhydrazine $(\mathrm{MMH})$ and Nitrogen tetroxide (NTO) at $11.3 \mathrm{lpm}$ are approximately $202 \mathrm{kPa}$ and $302 \mathrm{kPa}$, respectively [1]. The pressure-drop results are based on a single-phase flow. The receiving tank is required to vent from approximately $1827 \mathrm{kPa}$ to a lower pressure to affect propellant transfer. These pressure-drop scenarios cause the helium-saturated propellants to release excess helium. For tank ullage venting, the maximum volumes of helium evolved at tank pressure are approximately $0.5 \mathrm{ft}^{3}$ for $\mathrm{MMH}$ and $2 \mathrm{ft}^{3}$ for NTO. In micro-gravity environment, due to lack of body force, the helium evolution from a liquid body acts to propel it, which influences its fluid dynamics. For propellant transfer, the volume fractions of helium evolved at line pressure are $0.1 \%$ by volume for $\mathrm{MMH}$ and $0.6 \%$ by volume for NTO at 11.3 $\mathrm{lpm}$. The void fraction of helium evolved varies as an approximate second order power function of flow rate. This relationship implies a significant change in void fraction at higher flow rate $(>11.3 \mathrm{lpm})$, which transforms the single-phase flow to two-phase flow. The impact of two-phase flow is the increase in pressure drop. Moreover, when the propellant reaches the receiving tank, it experiences an abrupt pressure drop, which causes a high portion of excess helium to release. The accumulation of excess helium inside the receiving tank for 2,075-lbm transfer is insignificant; however, for $9000 \mathrm{lbm}$ transfer, the release of excess

' This work was performed under NASA Contract No. NAS15-10000 to develop ISSPM. 
helium causes the receiving tank pressure to increase by 24 psi, which effectively reduces its capacity to receive the propellant.

In summary, the effects of helium evolution from helium-saturated propellant are significant at high propellant transfer load $(9,000 \mathrm{lbm})$ and high transfer rates (> 11.3 (pm.)

\section{INTRODUCTION}

One of the technical challenges in developing a propellant transfer capability in space for an unbladdered propulsion system is the helium evolution from heliumsaturated propellant. The topic of gas evolution is not new; however, the effect it has on the propellant transfer in space is new. Most of us can relate to the concept of gas evolution from the experience of opening a carbonated beverage can under pressure. There is a manifestation of bubble foam discharging from the can. This bubble foam is the effect of carbon dioxide $\left(\mathrm{CO}_{2}\right)$ coming out of solution in the form of gas bubbles. Likewise, the process of helium coming out of helium-saturated propellant exhibits a similar phenomenon; however, it is to a lesser extent since the concentration of saturated gas in the two cases is significantly different. Furthermore, $\mathrm{CO}_{2}$ is involved in a chemical equilibrium interaction with water, while helium is inert.

Helium-saturated propellants generate helium gas due to pressure drop driven solubility changes. The effects of helium evolution include two-phase gas/liquid flow from the supply tank, gas injection into the receiving tank, and liquid discharge from the receiving tank.

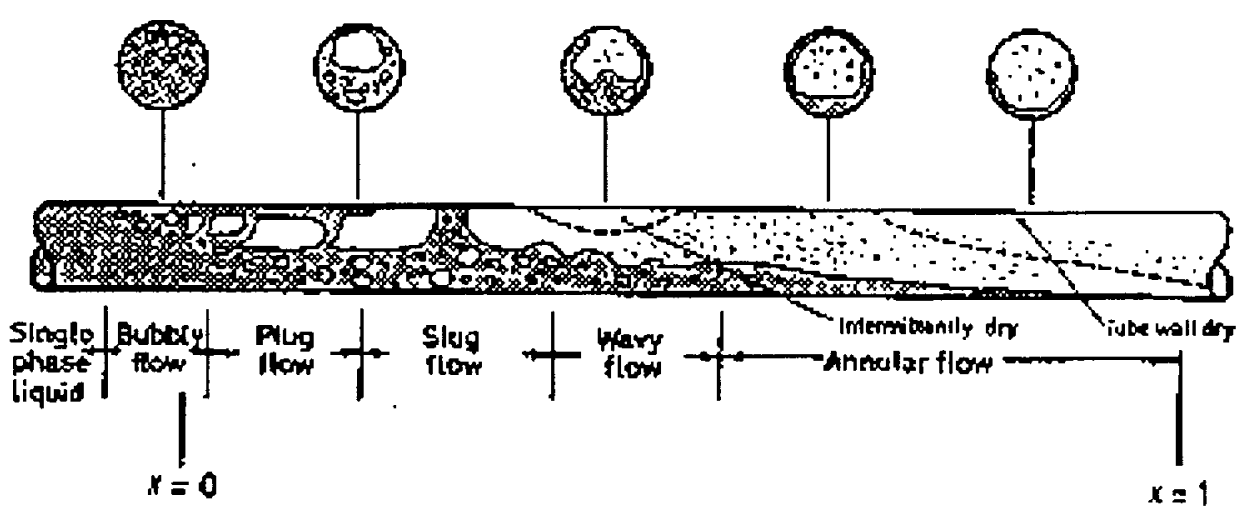

Figure 1. Flow Patterns in a Tube Showing the Effect of Helium Evolution [2]

The gas/vapor generation will occur as the liquid moves from the supply tank to the receiving tank under pressure gradients. This is similar to the problem encountered during depressurization of thruster systems ${ }^{2}$. Gas nucleates from structure, turbulent eddies, or within the bulk liquid and grow progressively with decreasing pressure. Figure 1 illustrates the problem of gas/vapor generation

NASA WSTF Report and Video of Hot Fire Test Series No. 3A of 12, February 1999, Run No. 19. 
along the transfer path. The gas/vapor density is orders of magnitude lower than the liquid density. This indicates that the two-phase flow entering the tank will have much less mass than that for all liquid entering.

Due to the lack of body forces in zero gravity, the mixture of gas/vapor and liquid floats freely. Because of the uncertainty in the gas/liquid location inside the tank, arbitrarily venting of the tank can be detrimental and counterproductive as the likelihood of venting liquid propellant overboard. Also, as pressure decreases in the tank, the liquid becomes super-saturated relative to the chemical or thermodynamic conditions of the fluid. In a storable propellant system, the noncondensable pressurant that was previously in solution begins to form bubbles within the bulk liquid. The result is the disturbance of the liquid/gas orientation within the tank and the subsequent uncertainty of all gas venting.

Implementation of on-orbit propellant transfer requires solving many problems including ullage venting without liquid migration to the vent (and consequent discharge of liquid) and inhibition of the filling process due to back pressure buildup before the tank is full. Both of these effects are related to the generation of gas or vapor with decreasing pressure. Gas evolution is a key issue for propellant tank stability, transfer line flow regime, pressure drops, and receiving tank pressure rise.

\section{PROPELLANT TRANFER APPLICATION}

The Boeing Corporation, under contract to NASA, was the prime contractor for the development of a refuelable, unbladdered Propulsion Module for the ISS, NASA Contract No. NAS15-10000, Figure 3. The ISSPM will provide the propulsive capacities for the ISS in conjunction with its Russian counterpart, the Service Module (SM). The analyses of helium evolution in this report are based on the requirements derived from this program.

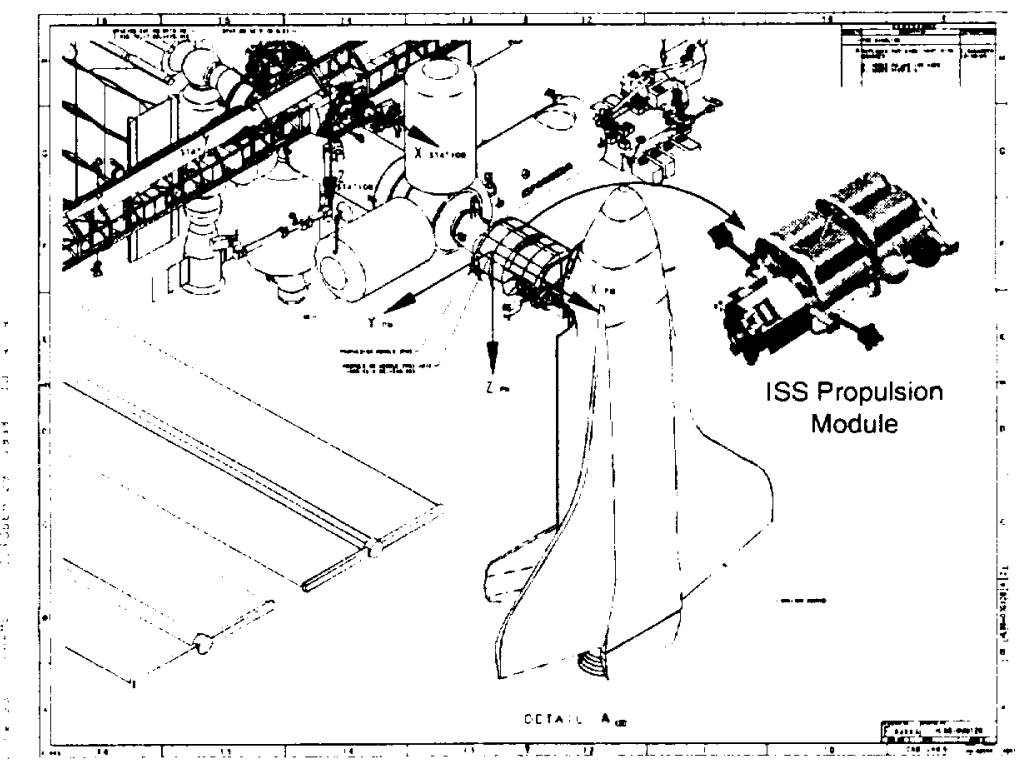

Figure 3. The Integrated ISSPM/ISS with Orbiter Docking Concept 
The ISSPM is a bi-propellant propulsion system, which utilizes

Monomethylhydrazine $\left(\mathrm{MMH}-\mathrm{CH}_{3} \mathrm{~N}_{2} \mathrm{H}_{3}\right.$ ) as a fuel and Nitrogen Tetroxide (NTO$\mathrm{N}_{2} \mathrm{O}_{4}$ ) as an oxidizer. The mission of the ISSPM is to provide the propulsive capabilities to perform altitude control, Control Moment Gyro (CMG) desaturation and reboost of the ISS under constraints of Design Reference Missions (DRM) 1, 2 and 3 requirements for an approximate duration of 12 years, Table 1.

Design Reference Mission Descriptions (Rev. B)

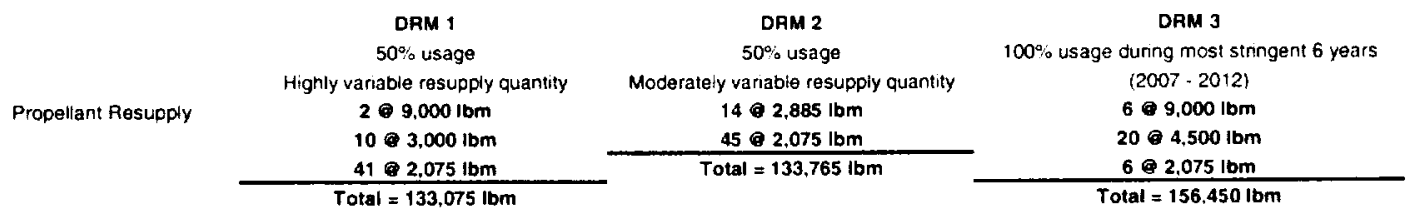

\begin{tabular}{|c|c|c|c|}
\hline 2002 (Year 1) & 12.660 & 12.660 & - \\
\hline 2003 (Year 2) & 8.816 & 8.816 & - \\
\hline 2004 (Year 3) & 1.979 & 1.979 & $\therefore$ \\
\hline 2005 (Year 4) & 7.951 & 7.951 & - \\
\hline 2006 (Year 5) & 9.580 & 9.580 & - \\
\hline 2007 (Year 6) & 8.996 & 8.996 & 17,992 \\
\hline 2008 (Year 7$)$ & 19,811 & 11.811 & 23.623 \\
\hline 2009 (Year 8) & 14.587 & 14.587 & 29,174 \\
\hline 2010 (Year 9) & 10.551 & 10.551 & 21,103 \\
\hline 2011 (Year 10) & 14,075 & 14.075 & 28,151 \\
\hline 2012 (Year 11) & 11,248 & 11,248 & 22,496 \\
\hline 2013 (Year 12) & 7.928 & 7,928 & - \\
\hline 2014 (year 13) & 1.285 & 1.285 & - \\
\hline Total & 121,468 & 121.468 & 142,538 \\
\hline
\end{tabular}

Note: Initial launch load is $42 \%$ of tank volume $(10,957 \mathrm{lbm})$

Table 1. Design Reference Mission for the ISSPM Program

To fulfil its mission objectives, the ISSPM will require propellant re-supply throughout its 12-year life. The Orbiter will supply the propellants stored in its Orbiter Maneuvering Subsystem (OMS) tanks [3], which are unbladdered tanks with built-in propellant acquisition device (PAD), Figure 4.

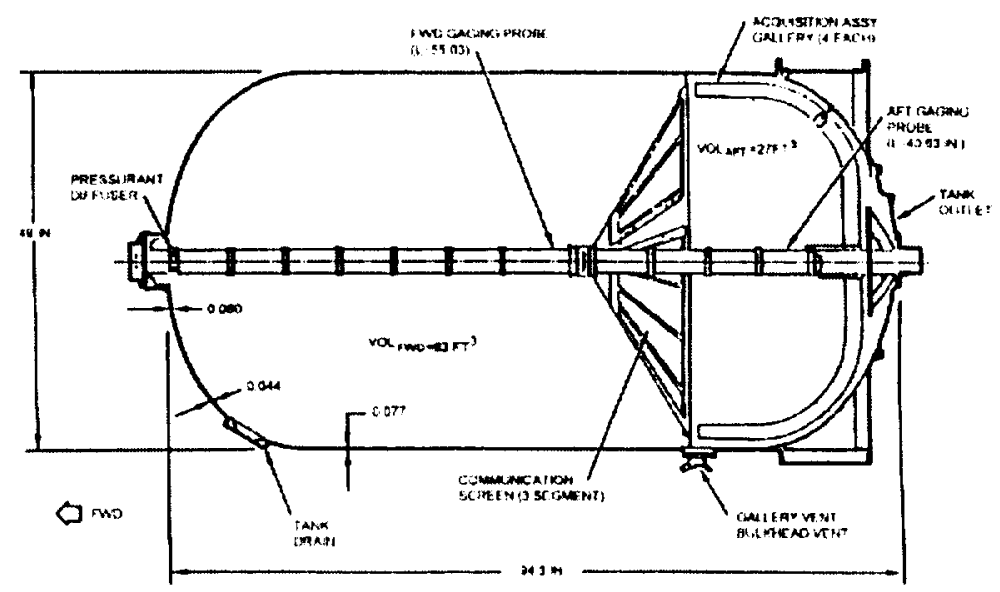

Figure 4. OMS Tank Configuration 
Transferring propellant from the Orbiter tanks to the ISSPM tanks is accomplished by creating a pressure difference between tanks. This requires that the receiving tank be initially vented. Venting and transferring heliumsaturated propellants in low-gravity condition are a challenge due to the effect of helium evolution. Figure 5 illustrates the end-to-end propellant transfer system between the Orbiter and the ISSPM.
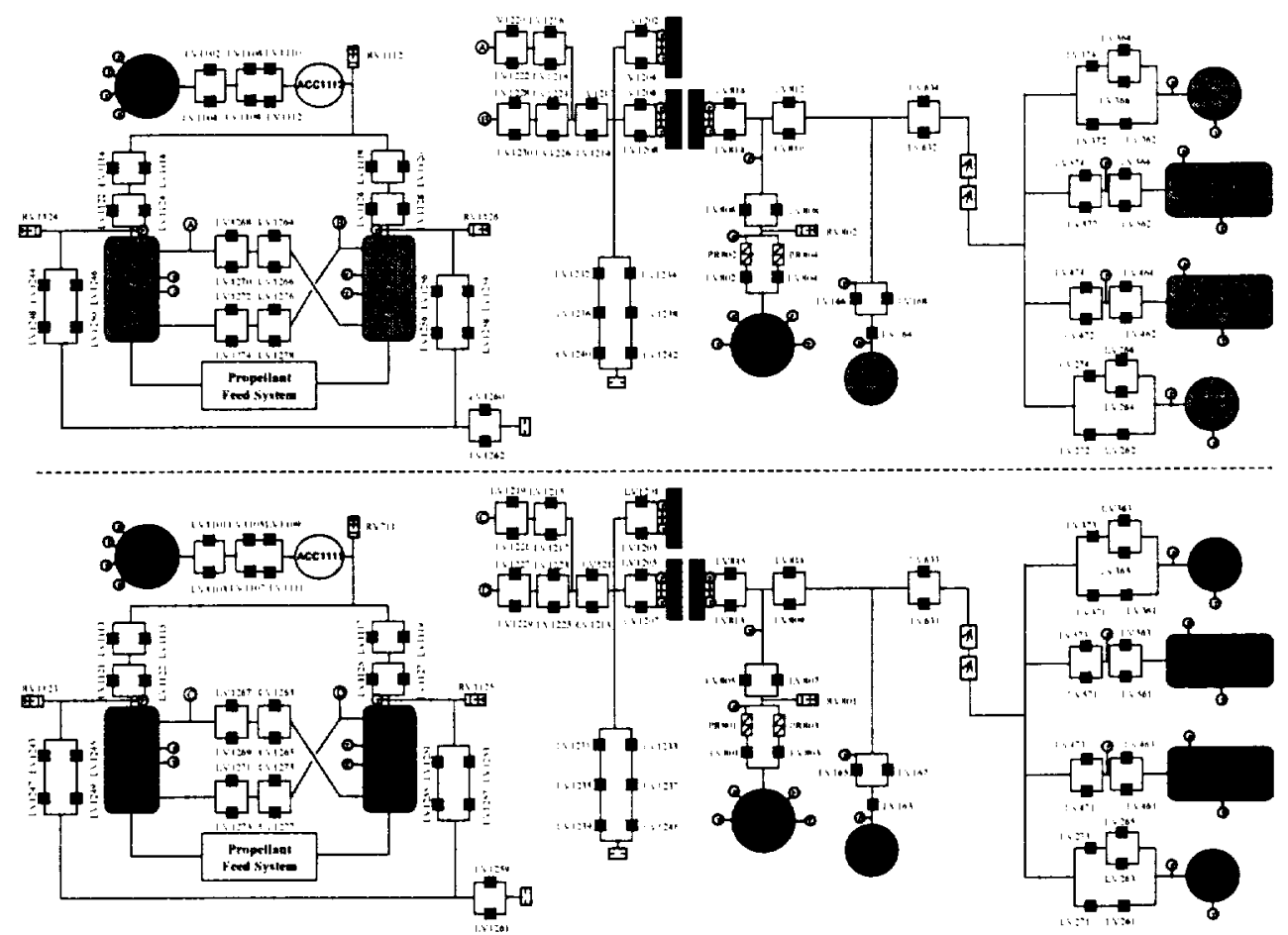

Figure 5. End-To-End Propellant Transfer System

\section{PROPELLANT TRANSFER CONDITIONS}

The Orbiter and ISSPM propellant tanks used in the transfer are assumed to be operated in a pressure regulated mode. The pressures are assumed to be 252 psia for an OMS to ISSPM transfer and 242 psia for a RCS to ISSPM transfer. This assumption is based on minimum pressure regulation values for the OMS/RCS regulators. Per OMS tank specification [3], the pressure of the ullage gas shall not exceed the operating pressure limits of the propellant tank, max/nom: $313 / 250 \pm 4$ psig. Furthermore, the flight bulk temperature is constrained by a temperature range from $40^{\circ} \mathrm{F}$ to $100^{\circ} \mathrm{F}$.

Per the DRM, the smallest propellant transfer load is $2,075 \mathrm{lbm}$, and the largest load is $9000 \mathrm{lbm}$, which corresponds to the maximum supply capability of the Orbiter. The ISSPM must be vented prior to the arrival of the Orbiter to minimize potential hazardous contamination to the Orbiter while it is docked with the ISS. The required pressure of the ISSPM tank for a transfer is a function of a predetermined supply load [4], Table 2. Consequently, not all required venting pressure is the same. 


\begin{tabular}{|c|c|c|c|c|c|c|c|c|c|c|c|}
\hline \multirow{2}{*}{$\begin{array}{l}\text { Ullage } \\
\text { Volume } \\
\left(\mathrm{ft}^{3}\right)\end{array}$} & \multirow{2}{*}{$\begin{array}{l}\text { Percentage } \\
\text { of Ullage } \\
\text { Volume } \\
(\%)\end{array}$} & \multicolumn{10}{|c|}{ Amount of Propellant Transfer, lbm } \\
\hline & & 3500 & 000 & 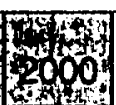 & 3000 & 4000 & 5000 & 6000 & 7000 & 8000 & 9000 \\
\hline & & (psia) & (psla) & (psia) & (psia) & (psia) & (psia) & (psia) & (psia) & (psia) & (psia) \\
\hline 81.90 & 89.6 & 239 & 228 & 3207 & 185 & 164 & 143 & 121 & 100 & 79 & 57 \\
\hline 72.40 & 80 & 238 & 226 & 202 & 178 & 154 & 130 & 106 & 82 & 58 & 34 \\
\hline 63.35 & 70 & 236 & 222 & 495 & 168 & 140 & 113 & 186 & 58 & & \\
\hline 54.30 & 60 & 234 & 218 & 186 & 154 & 122 & 90 & 58 & & & \\
\hline 45.25 & 50 & 231 & 211 & 173 & 135 & 96 & 58 & & & & \\
\hline 36.20 & 40 & 226 & 202 & 154 & 106 & & & & & & \\
\hline 27.15 & 30 & $218^{\circ}$ & 186 & 122 & & & & & & & \\
\hline 18.10 & 20 & 202 & 154 & 1 & & & & & & & \\
\hline
\end{tabular}

Table 2. Total Required Pressure as a Function of Propellant Load

The required pressure difference between tanks for propellant transfer is influenced by various factors. These factors are (1) the minimum delta pressure between tanks, (2) the line pressure drop, (3) the delta pressure due to helium evolution, (4) the delta pressure from temperature increase due to ullage compression, and (5) the delta pressure due to ullage compression. These factors oppose the ability to transfer propellant.

Thus, the required pressure difference between tanks can be written as: $\Delta P_{\text {required }}=(1) \Delta P_{\text {min }}+(2) \Delta P_{\text {line }}+(3) \Delta P_{\text {helium }}+(4) \Delta P_{\text {temp }}+(5) \Delta P_{\text {comp }}$

1. The minimum delta pressure between tanks

Propellant transfer is a time constraint process. The transfer rate has to be sufficient to facilitate the process. The transfer rate must therefore be more than a trickle flow. Since the mechanics of propellant transfer relies on the pressure difference, the transfer rate is limited by it. As the transfer process progresses, the pressure difference between tank decreases due to pressure built-up inside the receiving tank. As a result, the pressure built-up will reach a point where the flow rate deteriorates to a trickle flow. Hence, a minimum limit on the flow rate is necessary to facilitate the transfer operation. The minimum flow has been assumed to be approximately $0.5 \mathrm{gpm}$ to $0.6 \mathrm{gpm}$, which will be seen in the Propellant Load Scenarios Section. This minimum transfer rate imposes a minimum delta pressure requirement.

2. The line pressure drop

As the propellant travels along the transfer line, it experiences a pressure drop due to line friction, restrictions, and changes in flow direction. The line pressure drop must be overcome before propellant can be transferred. Furthermore, the pressure drop decreases monotonically as a function of transfer rate. 
3. The delta pressure due to helium evolution

When helium-saturated propellant depressurized, helium is evolved. This excess helium adds to the existing ullage helium/vapor, which causes the ullage pressure to increase. Increasing the mass of gas increases the pressure during ullage compression.

Furthermore, the system pressure drop as defined by a single-phase liquid will increase with the introduction of helium evolution. When helium evolves from the propellant, it begins as tiny bubbles from nucleation sites, turbulent eddies, and also within the liquid. Once these tiny bubbles are formed, they will grow progressively as a function of pressure drop. As the bubbles grow in size, they mix with the propellant liquid to create a two-phase flow. This phenomenon will facilitate turbulence in the flow, which changes the flow regime and increase the pressure drop in the line.

4. The delta pressure from temperature increase due to ullage compression

Compression of ullage gas during propellant transfer produces interfacial work done on the gas, which increases its internal energy. This phenomenon manifests in terms of temperature increase. As a result of temperature increase, the gas pressure increases accordingly. The delta pressure from this temperature increase opposes the transferring of propellant.

5. The delta pressure due to ullage compression

As the propellant is transferred into the receiving tank, it displaces the ullage gas volume. Consequently, the same amount of gas/vapor is successively compressed into a smaller volume. The result of this compression is the pressure increase. This is the main cause for the decrease in the pressure difference between tanks, which slows down the transfer rate.

It should be noted that the venting pressures in Table 2 were developed without considering some of the factors indicated above, for example, helium evolution. As a result, the vent pressures in Table 2 require adjustments to account for these factors.

\section{Propellants Load Scenarios [5]}

The propellant transfer scenarios analysis encompass the boundaries of required propellant transfer quantities as described in the Prime Item Development Specification (PIDS) (SSP 50479). The cases analyzed include both a 2,075 $\mathrm{lbm}$ and a $9,000 \mathrm{lbm}$ propellant transfer, Table 3 . The 2,075 lbm case was chosen because it is the minimum transfer case presented as part of the DRM described in Table 1. The 9,000 lbm case was chosen because it is the maximum transfer amount required by the PIDS requirements. 


\begin{tabular}{|c|c|c|c|c|c|c|c|}
\hline $\begin{array}{c}\text { Transfer } \\
\text { Case }\end{array}$ & $\begin{array}{c}\text { Propellant } \\
\text { Type }\end{array}$ & $\begin{array}{c}\text { FRCS } \\
(\mathbf{l b m})\end{array}$ & $\begin{array}{c}\text { RARCS } \\
(\mathbf{l b m})\end{array}$ & $\begin{array}{c}\text { LARCS } \\
(\mathbf{l b m})\end{array}$ & $\begin{array}{c}\text { ROMS } \\
(\mathbf{l b m})\end{array}$ & $\begin{array}{c}\text { LOMS } \\
(\mathbf{l b m})\end{array}$ & $\begin{array}{c}\text { TOTAL } \\
(\mathbf{l b m})\end{array}$ \\
\hline $\begin{array}{c}\text { Minimum } \\
(2075 \\
\text { (bm) }\end{array}$ & Oxidizer & 380 & 152 & 152 & 304 & 304 & 1292 \\
\cline { 2 - 8 } & Fuel & 230 & 92 & 92 & 184 & 184 & 782 \\
\hline $\begin{array}{c}\text { Maximum } \\
(9000 \\
\text { (bm) }\end{array}$ & Oxidizer & 669 & 160.5 & 160.5 & 2306.5 & 2306.5 & 5603 \\
\cline { 2 - 8 } & Fuel & 406 & 97.5 & 97.5 & 1398 & 1398 & 3397 \\
\hline
\end{tabular}

Table 3. Propellant Distribution in Orbiter Propellant Tanks Available for Transfer

\section{$\underline{2,075 \mathrm{lbm} \text { Transfer Analysis }}$}

Figure 6 shows the predicted flow rate profiles for the 2,075- $\mathrm{lbm}$ transfer. The peak flow rates are $1.26 \mathrm{gpm}$ NTO and $1.57 \mathrm{gpm} \mathrm{MMH}$. The minimum flow rates are $0.572 \mathrm{gpm}$ NTO and $0.600 \mathrm{gpm} \mathrm{MMH}$. These flow rates are produced by a pressure difference of approximately 80 psid between tanks. There are discontinuities in the flow due to the start and stop operations to prevent overheating of the ullage gas. The overheating occurs when the ullage temperature reaches $100^{\circ} \mathrm{C}$ limit. As the temperature approaches $100^{\circ} \mathrm{C}$, the transfer stops to allow the ullage to cool down. During propellant transfer, the ullage gas is successively compressed. Compression of the ullage gas causes heating due to the interfacial work done on the gas.

Flowrate vs. Time for $2075 \mathrm{lbm}$ Transfer, Fuel

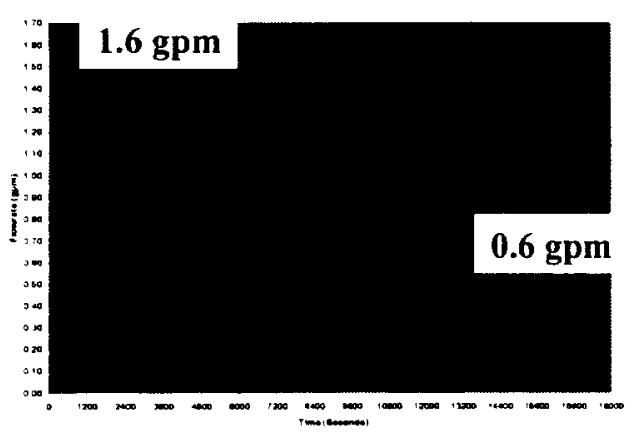

Flowrate vs. Time for $2075 \mathrm{lbm}$ Transfer, Oxidizer

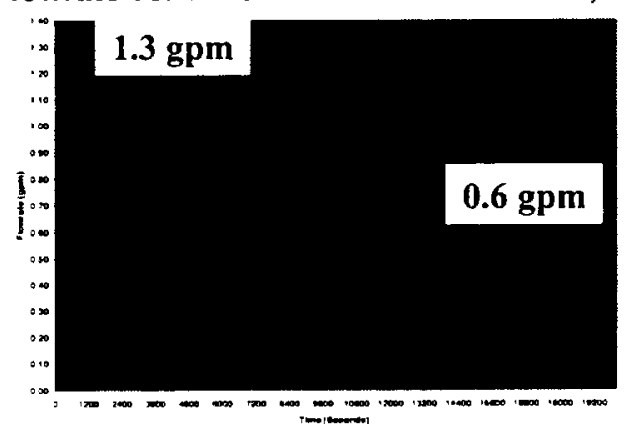

FIGURE 6. Flow Rate vs. Time for a 2,075 lbm Transfer, Fuel \& Oxidizer.

Figure 7 shows the predicted pressure rise for the 2,075-lbm transfer. The initial tank ullage pressure was 175 psia. This pressure was the result of venting the tank from 265 psia prior to transfer. It is the minimum required ullage pressure to affect a 2,075 lbm transfer. The predicted peak ullage pressures after the transfer are 224.73 psia NTO and 229.14 psia MMH. During the discontinuity in the transfer process, the ullage gas dissipates heat to its surrounding. As the temperature of the ullage gas decreases so does its pressure. This process can be seen in Figure 7 by the steps in the pressure curve. It should be noted that the peak pressure at the end of the transfer is constrained by the operating pressure limits of the propellant tank, max/nom: $313 / 250 \pm 4 \mathrm{psig}$. 
Pressure vs. Time for $2075 \mathrm{lbm}$ Transfer, Fuel Pressure vs. Time for $2075 \mathrm{lbm}$ Transfer, Oxidizer
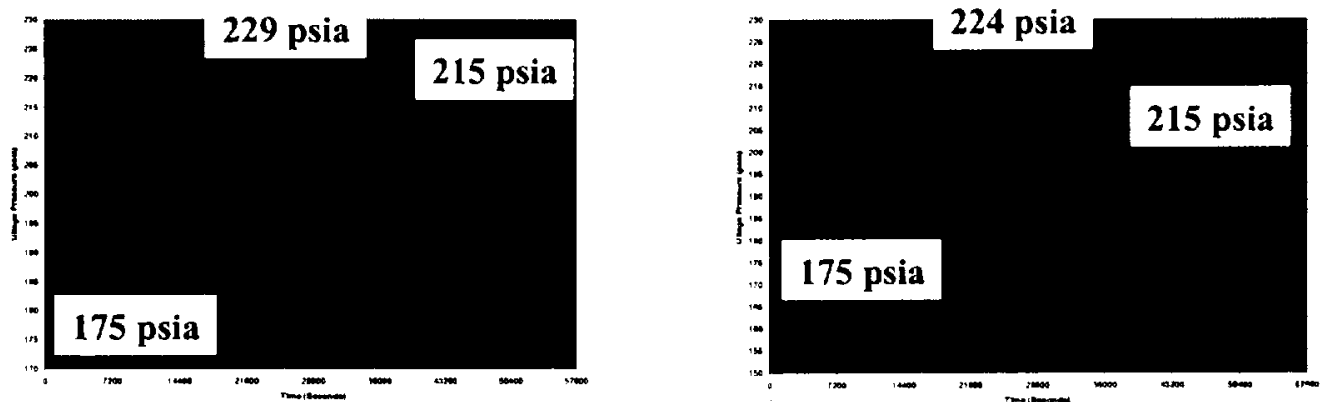

FIGURE 7. Pressure vs. Time for a $2,075 \mathrm{lbm}$ Transfer, Fuel \& Oxidizer.

\section{9,000 lbm Transfer Analysis}

Figure 8 shows the predicted flow rate profiles for the $9,000-\mathrm{lbm}$ transfer. The peak flow rates are $2.25 \mathrm{gpm}$ (NTO) and $2.81 \mathrm{gpm}(\mathrm{MMH})$. The minimum flow rates are $0.606 \mathrm{gpm}(\mathrm{NTO})$ and $0.658 \mathrm{gpm}(\mathrm{MMH})$. These flow rates are produced by a pressure difference of approximately 220 psid between tanks. Similarly, there are discontinuities in the flow as mentioned before. The duration between discontinuities is longer for the 9,000-lbm transfer than that of the $2,075-\mathrm{lbm}$ transfer. The $9,000-\mathrm{lbm}$ transfer requires a larger ullage volume to receive propellant. The larger ullage mass for the $9,000-\mathrm{lbm}$ transfer creates a higher thermal capacitance and larger surface area for heat sink to its surrounding, which requires a longer time to heat up to the same temperature, assuming a comparable heat rate for both cases.

Flowrate vs. Time for $9000 \mathrm{lbm}$ Transfer, Fuel

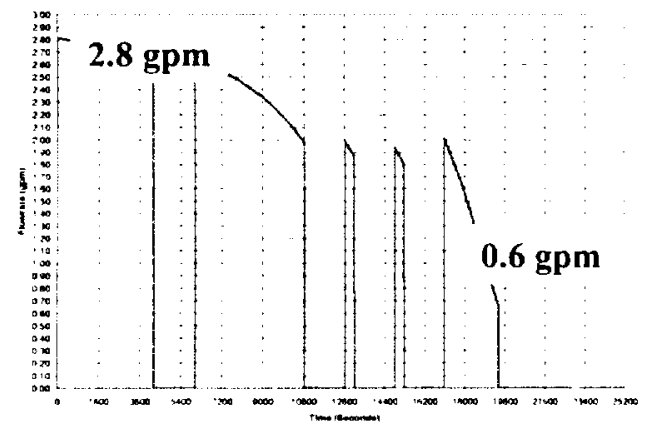

Flowrate vs. Time for $9000 \mathrm{lbm}$ Transfer, Oxidizer

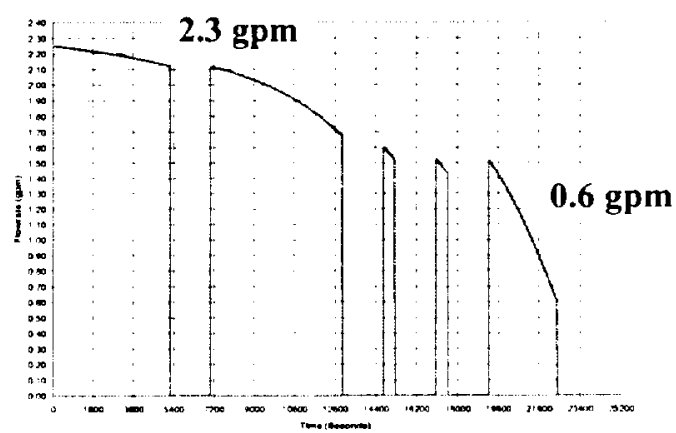

FIGURE 8. Flow Rate vs. Time for 9,000 lbm Transfer, Fuel \& Oxidizer.

Figure 9 shows the predicted pressure rise for the $9,000-\mathrm{lbm}$ transfer. The initial tank ullage pressure was 39 psia. This pressure is the result of venting the tank from 265 psia prior to transfer. It is the minimum required ullage pressure to affect a 9,000-lbm transfer. The predicted peak ullage pressures after the transfer are 222.97 psia (NTO) and 226.96 psia (MMH). Similarly, there are pressure steps occurring at the discontinuities in the flow. It is noted that following the peak pressure, there is a pressure decay to steady-state condition. This occurs as a result of heat dissipation from overheating due to ullage compression. 
Pressure vs. Time for $9000 \mathrm{lbm}$ Transfer, Fuel

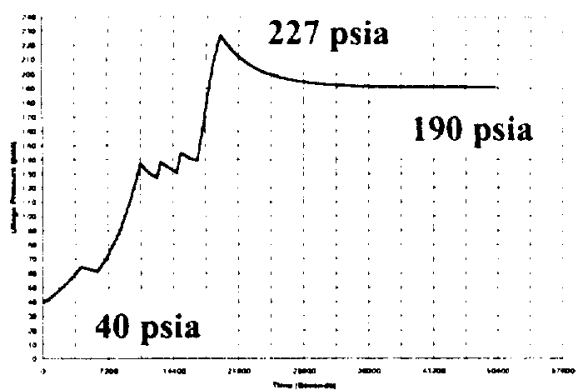

Pressure vs. Time for $9000 \mathrm{lbm}$ Transfer, Oxidizer

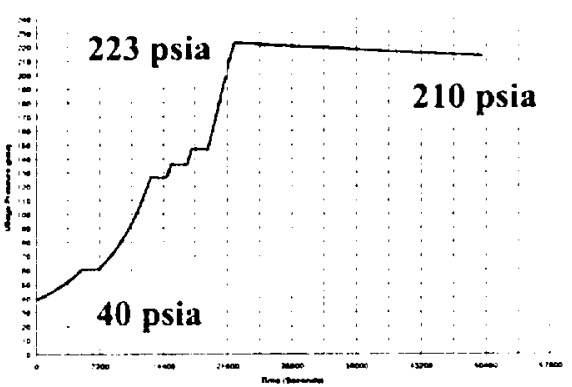

FIGURE 9. Pressure vs. Time for $9,000 \mathrm{lbm}$ Transfer, Fuel \& Oxidizer.

\section{ANALYTICAL APPROACH}

The helium evolution upon depressurization of a helium-saturated propellant occurs nearly instantaneously with respect to decreasing pressure, Table 4 . It is a technical challenge to measure the helium evolution rate as a function of time and pressure. Moreover, there is a lack of test data on the helium evolution rate. As an alternative, a steady-state helium evolution was used to determine the total amount of helium evolution and the steady-state time. The steady-state helium evolution approach is employed to determine the helium evolution in this paper.

\begin{tabular}{|c|c|c|c|c|c|}
\hline Propellant & $\begin{array}{c}\text { Amount } \\
(\text { gram })\end{array}$ & $\begin{array}{c}\text { Beginning Pressure } \\
(\mathrm{kPa})\end{array}$ & $\begin{array}{c}\text { De-saturation } \\
\text { Pressure (kPa) }\end{array}$ & $\begin{array}{c}\text { Absorption } \\
\text { Time (day) }\end{array}$ & $\begin{array}{c}\text { Evolution Time } \\
(\mathrm{min})\end{array}$ \\
\hline NTO & 95 & 1482 & 101 & 22 & $\sim 10$ \\
MMH & 59.5 & 1482 & 101 & 24 & $<1$ \\
\hline
\end{tabular}

Table 4. Steady-State Time Response of Helium Evolution from MMH and NTO

Helium-saturated propellants generate helium gas due to pressure drop driven solubility changes. The higher the pressure drop, the more helium evolution. Thus, the analysis of helium evolution requires a complete understanding of the pressure drop characteristics. For ullage venting, the pressure drop is characterized by the venting rate. For propellant transfer, the pressure drop is characterized by the resistance-to-flow.

\section{ANALYSIS OF HELIUM EVOLUTION}

Before beginning the analysis of helium evolution during propellant transfer, it is necessary to define the amount of helium absorption and evolution in $\mathrm{MMH}$ and NTO

\section{Helium Absorption $[6,7]$}

When propellant is pressurized with helium gas, the helium will be absorbed in the propellant. Reference [6] shows that the amount of helium saturated at 
standard temperature and pressure (STP) in MMH and NTO can be described by the following correlation:

$$
\begin{aligned}
& H e_{M M H}(P)=0.0006 P-0.00323 \\
& H e_{N T O}(P)=0.0022 P-0.0863
\end{aligned}
$$

The amount of helium absorption in the propellant increases with increasing pressure. NTO can absorb 3 to 4 times more helium at a given pressure than that for $\mathrm{MMH}$.

\section{Helium Evolution [6,7]}

Helium evolves when the helium-saturated propellant is depressurized. The lower the pressure, the larger the amount of helium will evolve. Reference [6] shows that the percentage of helium evolution upon depressurization can be described by the following correlation.

$$
\begin{aligned}
& \% \mathrm{He}_{\text {MMH }}(P)=-0.518 P+128.87 \\
& \% \mathrm{He}_{N T O}(P)=-0.474 P-118.47
\end{aligned}
$$

The percentage of helium evolution increases with decreasing pressure. The percentage of helium evolution is similar for both MMH and NTO even though the absorption capability varies by 3 to 4 times. The propellants were initially saturated with helium at 250 psig.

\section{Pre-Transfer Phase - Receiving Tank Venting}

Tank venting is necessary to implement the propellant transfer, which depends on the pressure difference between tanks to affect transfer. The factors which control the venting are (1) the propellant transfer load, Table 2, and (2) the temperature drop limits which are bounded by the acceptable flight bulk temperatures, $\max / \min : 100 / 40^{\circ} \mathrm{F}$. During ullage venting, the ullage gas expands from the reduction in pressure. As the gas expands, it expends interfacial work on its surrounding. As a result, its internal energy decreases. The reduction in its internal energy manifests in terms of its temperature drop. This temperature drop is constrained by its freezing point, which is approximately $62.27^{\circ} \mathrm{F}$ for $\mathrm{MMH}$ and

\section{Helium evolution analysis}

Consider an ullage volume $\mathrm{V}$ inside the receiving tank prior to venting. At time $t$, the residual propellant inside the tank is saturated with a fixed a mount of helium at approximately 265 psia. The amount of helium saturated within the propellant is defined as follows:

$$
X_{,}(265, V)=\left(\frac{14.7}{P}\right)(90-V) H e(265)
$$


At time $t+\Delta t$, the tank is vented to a pressure $P$. Since $P<265$ psia, helium gas will be evolved and the new amount of helium saturated within the propellant is defined as follows:

$$
X_{t+\Delta t}(P, V)=\left(\frac{14.7}{P}\right)(90-V) H e(P)
$$

The amount of helium evolved from the propellant during $\Delta t$ is determined as the difference in helium concentration in the propellant at 265 psia and at the current pressure.

$\Delta X=X_{t}-X_{t+\Delta t}=\left(\frac{14.7}{P}\right)(90-V)\left[X_{t}(265, V)-X_{t+\Delta t}(P, V)\right]$

For $\mathrm{MMH}$, the total steady-state helium evolution in venting from 265 psia to $P$ is $\Delta X_{M M H}=\left(\frac{14.7}{P}\right)(90-V)\left[X_{M M H}(265, V)-X_{M M H}(P, V)\right]$

Similarly, for NTO, the total steady-state helium evolution in venting from 265 psia to $P$ is

$$
\Delta X_{\text {NTO }}=\left(\frac{14.7}{P}\right)(90-V)\left[X_{\text {NTO }}(265, V)-X_{\text {NTO }}(P, V)\right]
$$

Figure 10 shows the results of helium evolution from helium-saturated propellants (MMH \& NTO) at 265 psia. It is clearly illustrated that the amount of helium evolution for NTO is approximately four times higher than that for MMH as expected. This is a result of higher saturation concentration of helium in NTO than that of $\mathrm{MMH}$. The percentage of propellant at the time of venting ranges from $80 \%$ by volume to $10 \%$ by volume. Alternatively, the percentage of ullage volume ranges from $20 \%$ by volume to $90 \%$ by volume. As the tank pressure decreases from 265 psia to a lower pressure, the amount of helium evolved increases as an inverse function of the pressure. It should be noted that the volume of helium evolved is under the same pressure as that of the tank. The dotted line in Figure 10 shows the limiting receiving capability of the tank at the corresponding percentage of ullage volume. The maximum volumes of helium evolved for MMH and NTO are approximately $0.5 \mathrm{ft}^{3}$ and $2 \mathrm{ft}^{3}$, respectively.

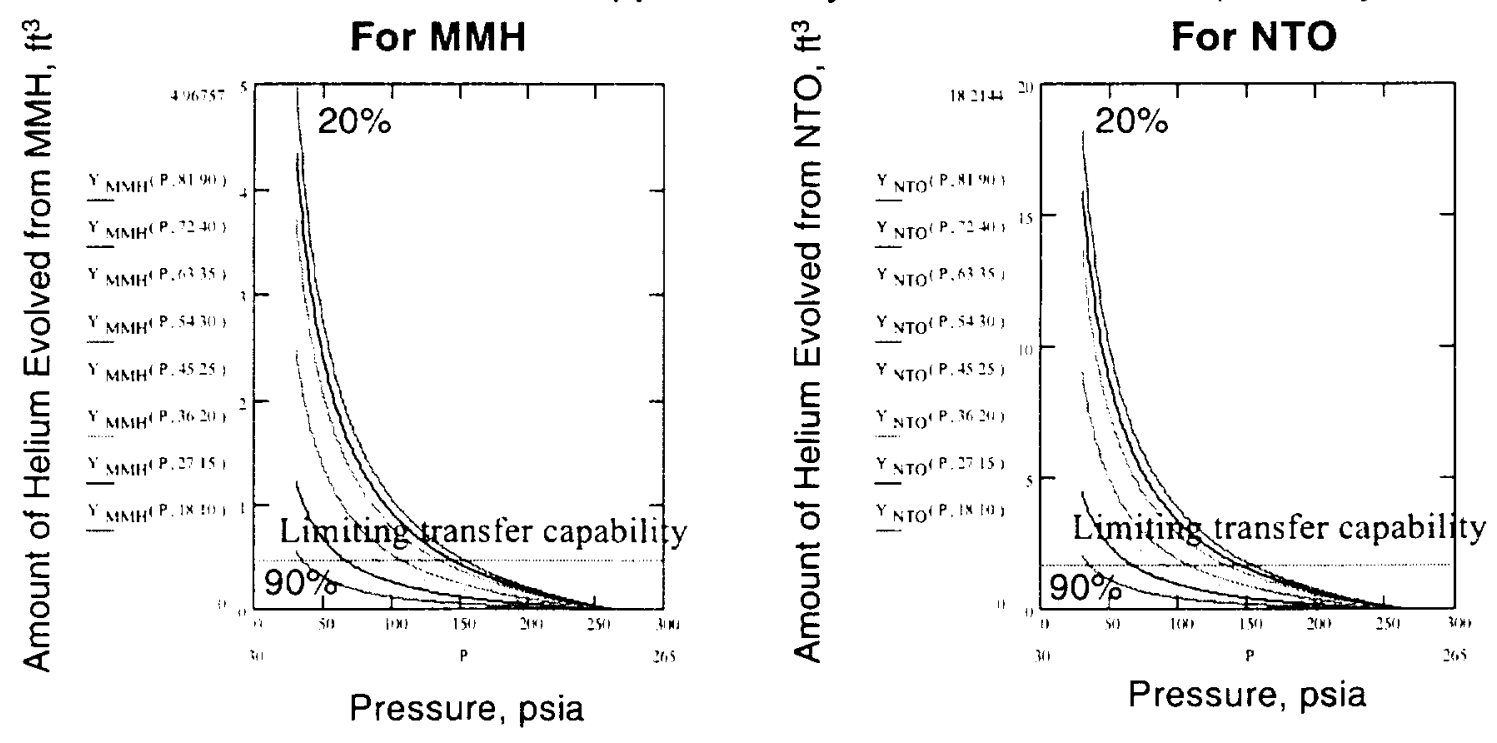

Figure 10. Helium Evolution during Ullage Venting from the Receiving Tank 


\section{Transfer Phase - Transferring Propellant from the Orbiter to the ISSPM}

At the completion of the pre-transfer phase, the receiving tank has presumably achieved the required pressure to commence the propellant transfer. The transfer begins at a peak flow rate and subsequently drops to a minimum. The minimum flow is necessary to facilitate propellant transfer. It was chosen to be approximately 0.5 gallon per minute as indicated in Figures 6 and 10 .

Since the pressure-drop characteristics in the transfer line and in the receiving tank are different, it is appropriate to separate the analyses into two sections: (1) helium evolution inside the transfer line and (2) helium evolution inside the receiving tank.

\section{- Helium Evolution Inside the Transfer Line}

Reference [1] provides a complete discussion of the helium analysis during propellant transfer in the transfer line. Here is the summary.

\section{Volume Fraction of Helium to Propellant upon Propellant Transfer}

The volume fraction of helium to propellant is defined as the ratio of the volume of the helium evolved at line pressure to that of the line (or propellant) volume from the supply tank to $\mathrm{x}$. The line volume is $V(x)=V_{\text {prop }}(x)+V_{\text {helium }}(x)$ at pressure.

Since $V_{\text {prop }}(x) \gg>V_{\text {helium }}(x)$, the line volume can be approximated as $V(x) \approx V_{\text {prop }}(x)$.

Total amount of helium evolution for $\mathrm{MMH}$ at line pressure

$$
\begin{aligned}
& R_{M M H}(x)=\left(\frac{101}{100 P x}\right)_{0}^{x} \% H e_{M M H}(P)\left(H e_{M M H}(P)+\frac{d H e_{M M H}(P)}{d P} \frac{d P}{d x} x\right) d x+ \\
& \left(\frac{101}{100 P x}\right) \int_{0}^{x} \int_{0}^{x}\left(H e_{M M H}(P)+\frac{d H e_{M M H}(P)}{d P} \frac{d P}{d x} x\right)\left(\frac{d\left(\% H e_{M M H}(P)\right)}{d P} \frac{d P}{d x}\right) d x d x
\end{aligned}
$$

Similarly, for NTO

$$
\begin{aligned}
& R_{N T O}(x)=\left(\frac{101}{100 P x}\right) \int_{0}^{x} \% H e_{N T O}(P)\left(H e_{N T O}(P)+\frac{d H e_{N T O}(P)}{d P} \frac{d P}{d x} x\right) d x+ \\
& \left(\frac{101}{100 P x}\right)_{0}^{x} \int_{0}^{x}\left(H e_{N T O}(P)+\frac{d H e_{N T O}(P)}{d P} \frac{d P}{d x} x\right)\left(\frac{d\left(\% H e_{N T O}(P)\right)}{d P} \frac{d P}{d x}\right) d x d x
\end{aligned}
$$


MMH: helium evolution

at line pressure

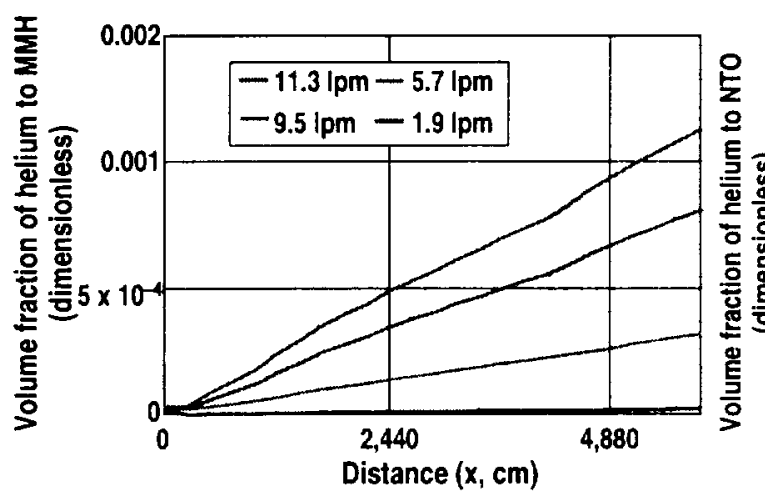

NTO: helium evolution

at line pressure

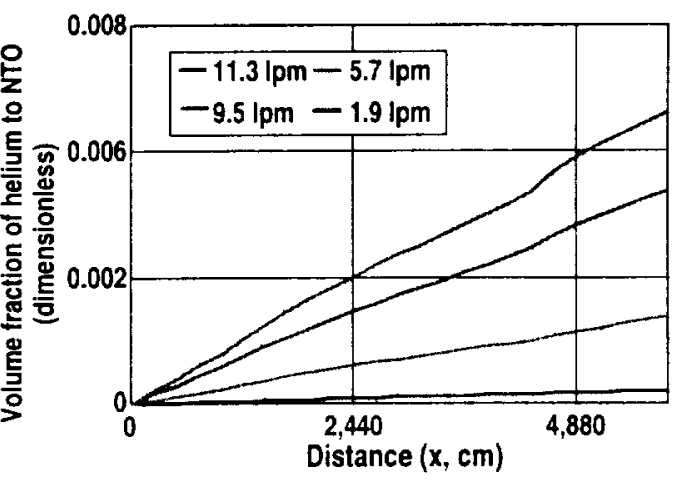

Figure 12. Volume Fraction of Helium to Propellant at Line Pressure inside the Transfer Line

Figure 8 shows the volume fraction of helium to $\mathrm{MMH}$ in the transfer line. The volume fraction of the helium gas evolution is approximately $0.1 \%$ of the line volume at $11.3 \mathrm{lpm}$. That is, for every cubic inch of the transfer line, there is a $1 / 1000$ in. $^{3}$ of the helium gas. The total transfer line volume is approximately $7722 \mathrm{cc}$. The total volume of the helium gas evolution at line pressure is approximately $8.19 \mathrm{cc}$. This is equivalent to approximately $0.5 \mathrm{in}^{3}$.

Figure 9 shows the volume fraction of helium to NTO in the transfer line. The volume fraction of helium is approximately $0.6 \%$ of the line volume at $11.3 \mathrm{lpm}$. That is, for every cubic inch of the transfer line, there is a $6 / 1000$ in. ${ }^{3}$ of the helium gas. For a line volume of $7722 \mathrm{cc}$, the total volume of the helium gas evolution at line pressure is approximately $45.88 \mathrm{cc}$. This is equivalent to approximately 2.8 in. $^{3}$.

\section{Correlation between the Void Fraction and the Volumetric Flow rate at the Outlet of the Transfer Line}

The void fraction is defined as the gas core cross-sectional area to the line cross-sectional area; that is, $\alpha=\frac{A_{\text {gas }}}{A}=\left(\frac{r_{g a s}}{r}\right)^{2}$

The void fraction is plotted as a function of flow rate for both MMH and NTO to further understand the potential impact of helium evolution at higher transfer rate, Figure 11. This report focuses on low transfer rate, up to $11 \mathrm{lpm}$. The results do not suggest major problem with flow regime; however, since the pressure drop increases as a second order power of the transfer rate, the impact of helium evolution is more significant as shown in Figure 11. Consequently, there is a limit to the transfer rate due to increase in helium evolution. The increase in helium evolution changes the pressure drop characteristics in the line from two-phase flow. The line pressure drop impacts the transfer operating capability. 
Void Fraction as a Function of Plow

Rute (MMH)

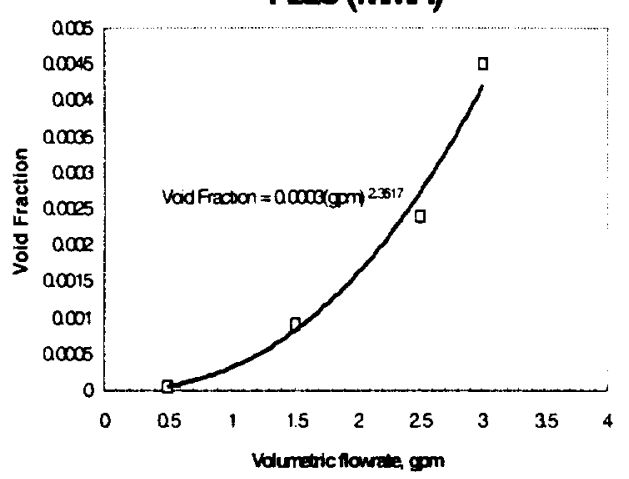

Void Fraction as a Function of Pow

Rate (NTO)

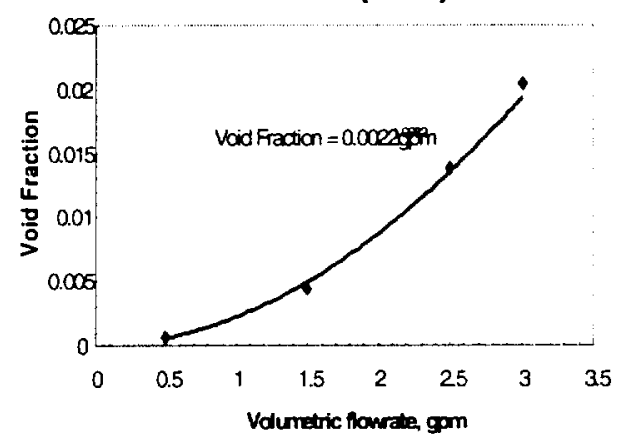

Figure 11. Correlation between Volume Fraction and Flow Rate

\section{- Helium Evolution Inside the Receiving Tank}

When the supply propellant enters the receiving tank, it experiences a sudden pressure drop. The line pressure drop is a small fraction of the pressure difference between tanks at high transfer load. At high transfer load, the pressure difference between tank is approximately 231 psid as compared to approximately $35 \mathrm{psi}$ inside the line. Since the pressure drop inside tank is much higher than that of the line, the amount of helium releases inside the tank is significantly higher at higher transfer load. The following analysis will quantify the amount of helium evolution inside the receiving tank.

\section{Helium evolution analysis}

Consider an elemental volume entering the tank. At time $t$, an elemental volume, $\Delta V$, is at the tank inlet with pressure $P_{o}$. This elemental volume of propellant is saturated with a fixed a mount of helium. The amount of helium saturated within the $\Delta \mathrm{V}$ is defined as follows:

$X_{t}=H e\left(P_{0}\right) \Delta V$

At time $t+\Delta t$, the elemental volume, $\Delta V$, is inside the tank with pressure $P(t)$.

Since $P_{o}>P(t)$, helium gas will be evolved from $\Delta V$ and the new amount of helium saturated within the $\Delta V$ is defined as follows:

$X_{t+\Delta t}=H e(P) \Delta V$

The amount of helium evolved from $\Delta \mathrm{V}$ during $\Delta \mathrm{t}$ is determined as follows:

$\Delta X=X_{t}-X_{t+\Delta t}=\left[H e\left(P_{0}\right)-H e(P)\right] \Delta V$

The total amount of helium evolved during the propellant transfer can be determined by summing all the $\Delta \mathrm{V}$ 's:

$$
\begin{aligned}
& X=\lim _{\Delta V \rightarrow 0} \sum \Delta X=\lim _{\Delta V \rightarrow 0} \sum\left[H e\left(P_{0}\right)-H e(P)\right] \Delta V=\int\left[H e\left(P_{0}\right)-H e(P)\right] d V \\
& X(t)=\int\left[H e\left(P_{0}\right)-H e(P)\right] \frac{d V}{d t} d t=\int\left[H e\left(P_{0}\right)-H e(P)\right] m(t) d t
\end{aligned}
$$

where $m(t)$ is the volumetric flow rate 
Hence, the amount of helium evolved inside the receiving tank can be calculated by integrating the difference in the concentration of the helium saturated in the propellant before and after it enters the tank.

For $\mathrm{MMH}$, the amount of helium evolution inside the tank at tank pressure is $X(t)=\left(\frac{0.1337}{60}\right)\left(\frac{14.7}{P}\right) \int\left[H e_{M M H}\left(P_{0}\right)-H e_{M M H}(P)\right] m_{M M H}(t) d t$

Similarly, for NTO, $X(t)=\left(\frac{0.1337}{60}\right)\left(\frac{14.7}{P}\right)\left[\left[H_{N T O}\left(P_{0}\right)-H e_{N T O}(P)\right] m_{N T O}(t) d t\right.$

where $P_{0}=265$ psia

\section{Case 1: A 2,075-Ibm transfer}

The propellant at the supply tank is saturated with helium at approximately 265 psia. As the propellant flows from the supply tank at 265 psia to the receiving tank at a lower pressure, it releases helium. The evolved helium will subsequently build up inside the receiving tank. During the propellant transfer, the supply propellant compresses the original gas/vapor inside the receiving tank. In addition, the evolved helium from the supply propellant increases the compressed pressure in the tank, Figure 14.
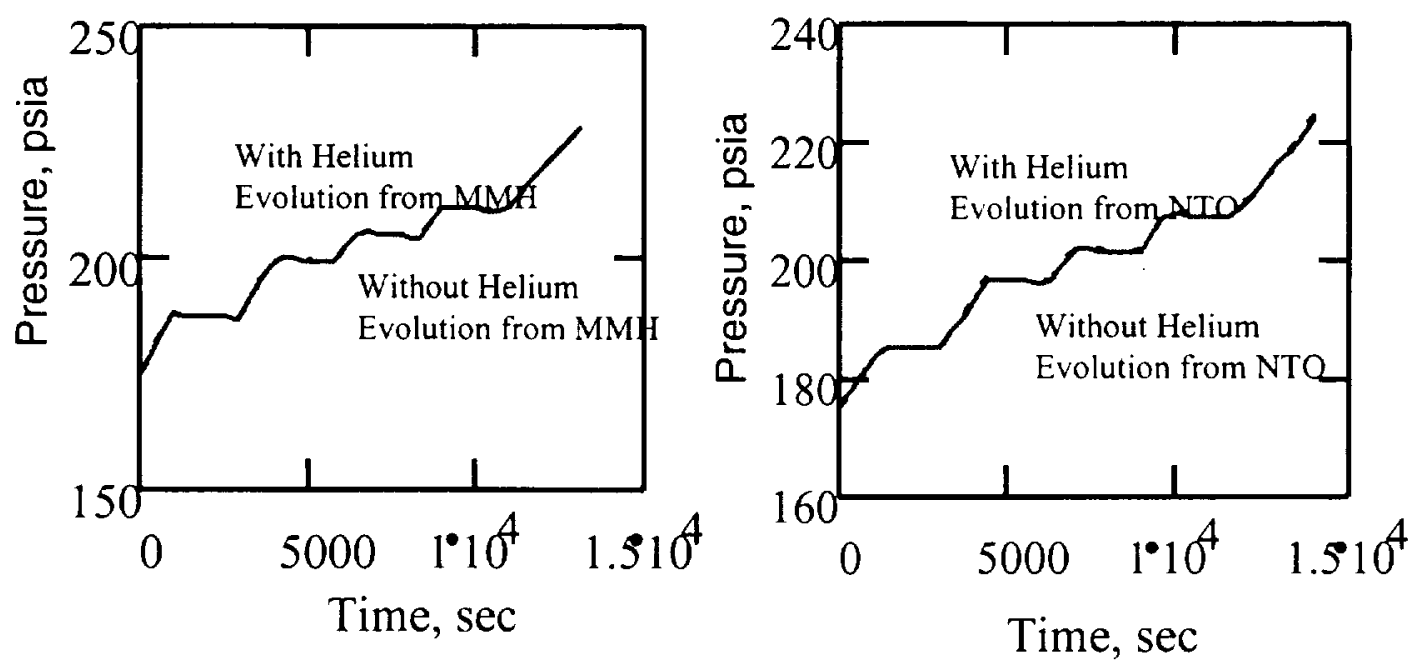

Figure 13. Pressure Built-up Inside the Receiving Tank from Excess Helium Evolution for a 2,075-lbm Transfer

The results from Figure 13 show that there is no significant pressure rise from the addition of evolved helium from the supply propellant at this load. 


\section{Case 1: A 9,000-Ibm transfer}

Similarly, the results of the $9,000-\mathrm{lbm}$ propellant transfer are shown in Figure 15.

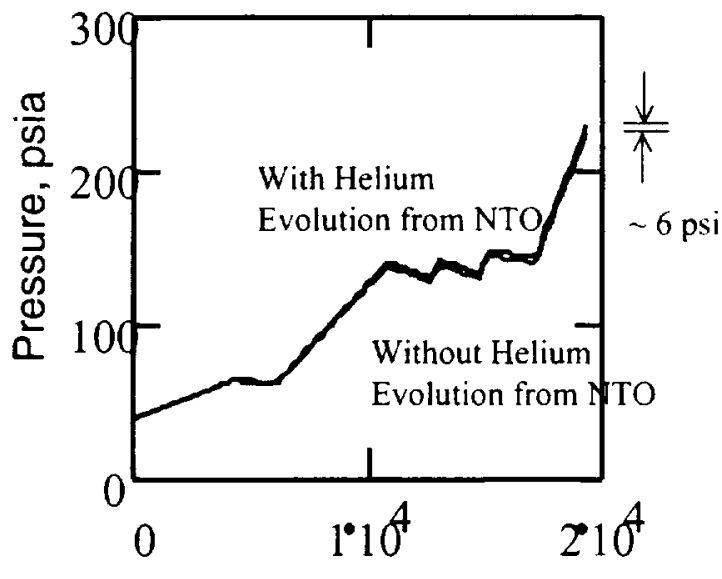

Time, sec

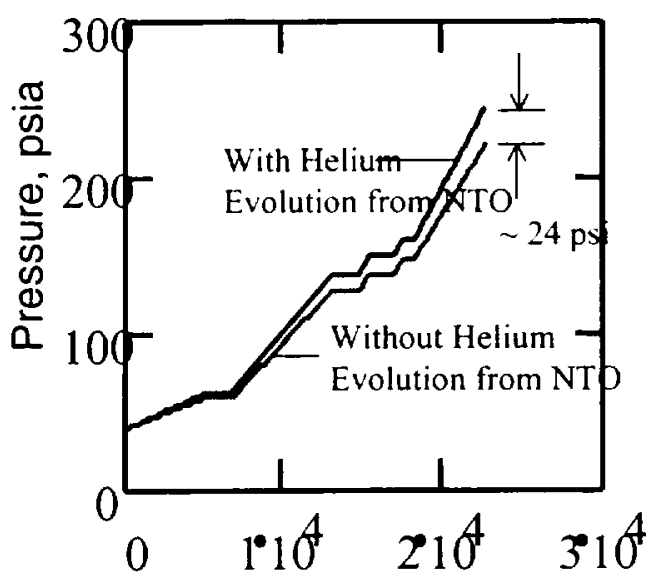

Time, sec

Figure 14. Pressure Built-up Inside the Receiving Tank from Excess Helium Evolution for a 9,000-lbm Transfer

Figure 14 indicates that the effect of helium evolution for a $9,000-\mathrm{lbm}$ transfer is significant. For MMH, the evolved helium compresses to 6 psi. For NTO, the evolved helium compresses to $24 \mathrm{psi}$. These pressures have to be accounted for during ullage venting so that the required supply propellant can be transferred into the receiving tank.

\section{CONCLUSIONS}

The effects of helium evolution are significant at high transfer load $(9,000 \mathrm{lbm})$ and high transfer rate $(>11,3 \mathrm{lpm})$. Since helium evolution problem is inherent in the helium-saturated propellant for an unbladdered tank system, it is important to address and to characterize it so that a resolution can be defined. Depend on the transfer scenario, the effect of helium evolution is more significant in one aspect of the transfer than others. However, its impact is well identified. Further work is necessary to determine its impact on the fluid dynamics during venting, for example, the kinetic rate of helium evolution. The release of helium from a liquid body in micro-gravity environment can induce dynamic force, which influences its overall dynamic behavior. The concern of venting liquid overboard emphasizes the need for a better understand of the fluid dynamics when venting is commenced. This is perhaps the most challenging topic in the helium evolution analyses.

\section{REFERENCES}

1. Bich N. Nguyen, and Frederick Best, "Helium Evolution from the Transfer of Helium-Saturated Propellant In Space," MDC 00H1564, October 2000, $21^{\text {st }}$ Space Simulation Conference.

2. John Collier, "Convective Boiling and Condensation," second edition, McGraw-Hill Book Company, 1981. 
3. The Boeing Company, "Space Shuttle Orbiter - Orbiter Maneuvering Subsystem Smart Book," March 1991, Huntington Beach, CA.

4. J. Justin, "International Space Station Propulsion Tank Venting Timeline Analysis," The Boeing Company: PM DPDR1-0084, April 2000, Huntington Beach, CA.

5. J. H. Newton, "International Space Station Propulsion Module Propellant Transfer Timeline Analysis," The Boeing Company: PM DPDR1-0083, April 2000, Huntington Beach, CA.

6. I. D. Smith, "The Determination of the Helium Saturation Level of Monomethylhydrazine and MON-3 Nitrogen Tetroxide", Lyndon B. Johnson Space Center White Sands Test Facility, Document No. TR-244-001, 1979.

7. K. Coolidge, "Helium Solubility Rates in NTO and MMH", Report No. 287-20181-086, Rockwell International, 1981. 